\title{
Educação Comunitária: da Animação ao Desenvolvimento
}

\section{Community Education: from Animation to Development}

\author{
Lurdes Pratas Nico*, Bravo Nico* \\ Universidade de Évora
}

\begin{abstract}
Resumo
A Escola Comunitária de São Miguel de Machede, fundada em 1998, tem vindo a promover o desenvolvimento humano, social e económico, assumindo a educação não formal, como instrumento da sua concretização. A atividade da Escola Comunitária ocorre nas seguintes dimensões: o apoio social, o reforço da identidade local, a promoção do sucesso escolar dos jovens, a qualificação dos adultos, a mobilização dos recursos endógenos, a valorização e divulgação da cultura local, o envelhecimento ativo e saudável, a criação de trabalho jovem e qualificado e a concretização de projetos e atividades que privilegiam o trabalho e a cooperação intergeracionais.

Palavras-Chave: Educação Comunitária, Animação, Desenvolvimento
\end{abstract}

\begin{abstract}
The Community School of São Miguel de Machede, founded in 1998, has been promoting human, social and economic development, assuming non-formal education as an instrument for its implementation. The activity of the Community School takes place in the following dimensions: social support, strengthening of local identity, promoting the success of the school for young people, qualification of adults, mobilization of endogenous resources, valorization and dissemination of local culture, active aging And healthy, the creation of young and qualified work and the realization of projects and activities that privilege intergenerational work and cooperation.

Keywords: Community Education, Animation, Development
\end{abstract}

\section{Educação: um direito humano exercido em contextos humanos}

$\mathrm{Na}$ atualidade, considera-se que a educação é um direito fundamental de qualquer pessoa, porque se assume como um dos vetores estruturantes e indispensáveis para promover e sustentar o seu desenvolvimento (Arroteia, 2008, p.41; Silva, 1990, p.34; Araújo, 2010, p.166), criando-lhe e garantindolhe as condições necessárias para uma, ativa e consciente, participação nos processos de decisão, nas dimensões individual e coletiva que determinam o seu percurso vital. Nesta perspetiva, a educação é um processo que: dura toda a vida, tentando envolver a totalidade do ser e levando-o à participação activa na criação da cultura, da técnica, da ciência, do bem-estar, da riqueza, da paz, da cooperação internacional, enfim, realizando o indivíduo como pessoa e como membro de uma comunidade mundial (Loureiro, Marques \& Vallgarda 1983, p.19).

Neste amplo entendimento daquilo que, na atualidade, representa a educação, na construção dos alicerces de uma cidadania informada, ativa e participante, facilmente se depreende que, nos pequenos contextos comunitários - territorialmente delimitados e, social, cultural e economicamente, definidos -, os processos de desenvolvimento se devem ancorar na mobilização das pessoas, através da respetiva qualificação e valorização. Este movimento de qualificação passa, naturalmente, pela consideração, valorização e articulação de todas as modalidades de educação e formação, dos contextos escolares e formais às dimensões menos formais e mais conviviais, próprias de ecossistemas humanos em que a relação humana e social ainda se mantém ativa e onde as relações entre as pessoas são uma rede que não deve ser desvalorizada.

Por outro lado, os processos educativos que se desenham e concretizam, nos contextos comunitários nomeadamente os que se localizam em regiões de baixa densidade demográfica e de povoamento concentrado, como é o caso da região sul de Portugal - são oportunidades nas quais se devem convocar os saberes locais, frequentemente caracterizados pelo seu perfil menos formalizado, pouco científico e com uma base didática baseada na oralidade. Estes conhecimentos são, por outro lado, parte fundamental do património cultural local, tendo resultado de, longos, participados e valorizados, processos de ensino e aprendizagem, nos quais a intergeracionalidade desempenhou um papel decisivo. Esta dimensão da consideração, valorização e mobilização dos saberes locais é uma, outra e incontornável, dimensão do Direito à Educação: o Direito a uma Educação que inclui os conhecimentos e as didáticas próprias dos territórios e das comunidades e que valoriza o papel de todas as gerações, nos processos educativos em que se garante a transmissão dos legados culturais entre as gerações. 
Como referiu Dewey (1979: 83, citado por Libâneo, 1998, p. 67), a educação não é a preparação para a vida, mas é a própria vida, num processo que, segundo aquele autor, integra a experiência e a teoria, a observação e a ação. É neste, complexo e sistémico, contexto humano que ocorre o desenvolvimento humano, que se revela, quando os indivíduos conduzem as suas vidas de um estado para outro (Libâneo, 1998, p.64), como resultado das suas vontade, capacidade e decisão próprias e quando ocorre a mudança de representações e comportamentos, aos níveis individual e coletivo (Silvestre, 2003, p.184).

Concretizar o exercício do Direito à Educação, nos contextos humanos em que as pessoas vivem e desenvolvem a sua atividade - qualquer que seja a dimensão pessoal considerada -, significa que se garante, a cada cidadão, a possibilidade de participar na definição da sua vida pessoal e de contribuir na definição da vida coletiva da sua comunidade. Esta possibilidade de intervir na realidade e de, com o seu contributo, sentir que pode, de facto, participar na sua transformação, é uma das dimensões mais importantes e estruturantes do exercício do Direito à Educação.

Por outro lado, a aprendizagem é, cada vez menos, um processo circunscrito aos momentos iniciais da vida e confinado aos espaços escolares (Alves, Cabrito, Canário \& Gomes, 1996, p.47). Assumindo-se como um processo contextual (Quintas, 2008, p.30), a aprendizagem ocorre em todos os espaços e momentos vitais, nos quais, em cada episódio educativo concretizado, a pessoa é o principal recurso da sua própria formação (Canário, 1999, citado por Casimiro, 2011, p.44; Smith, 1997, p.17), "desempenhando a experiência um papel de âncora na realização de novas aprendizagens" (Trigo, 2001b, p.103).

Neste contexto, o tempo da educação é o tempo da vida, porque a educação é "algo que fazemos na, com e da nossa vida" (Patrício, 1982:76). Assim sendo, em cada ciclo vital, cada pessoa necessita e procurará concretizar o conjunto de aprendizagens que lhe proporcionará as melhores condições para realizar o seu projeto de vida.

\section{Animação e Educação Comunitária}

A Animação, nas suas diversas declinações conceptuais e práticas, é uma abordagem metodológica que tem vindo a ser utilizada, com alguma frequência, nas últimas décadas, em muitos projetos de natureza comunitária que assumem a educação como eixo estruturante do desenvolvimento local.

São frequentes, na literatura especializada, nos documentos legais, na comunicação social e noutros formatos comunicacionais, as referências a termos como Animação Sociocultural, Animação Educativa, Animação Socioeducativa, Animação Comunitária, Animação Sociocomunitária. Independentemente da abordagem conceptual assumida, um dos elementos estruturantes dos processos de Animação reside no facto de esta abordagem contemplar a possibilidade de participação ativa de um elemento externo, nos contextos objeto de intervenção, que atua de acordo com a estratégia definida (Rothes, 1993, p.28; Sarramona, 1998, p.152).

Neste pressuposto, os processos de Animação, em cada contexto comunitário e territorial, assumem alguns desafios, no âmbito da sua missão de promoção do desenvolvimento:

a) Nas redes locais existentes (associações da sociedade civil, meios de comunicação social, redes digitais, espaços públicos, empresas, instituições políticas), promovem a gestão solidária do conhecimento (científico, académico, popular), das capacidades e das disponibilidades existentes, enquanto mediador e construtor de compromissos sociais (Gadotti, 2006, p.207-209);

b) Promoverão a aprendizagem em rede e nas redes, de forma não hierarquizada e cooperativa, promovendo as capacidades de colaboração, comunicação, pesquisa e pensamento;

c) Mobilizarão as vontade e capacidade de aprender, assumindo a aprendizagem como instrumento, individual e coletivo, de mudança e desenvolvimento (Berbaum, 1992, p.29);

Nos processos de Animação, consideram-se, normalmente, numa primeira fase, os recursos existentes nas próprias comunidades e contextos locais objeto da intervenção, nos quais sobressaem as instituições locais (Trilla, 2004, p.34). Numa segunda fase, consideram-se os recursos que vão resultando da própria intervenção (Marchioni, 1997, referido por Lopes, 2006, p.374) e que vão sendo incorporados no portefólio coletivo de possibilidades, aumentando, dessa forma, a capacidade da comunidade em fazer face a desafios de maior magnitude e reveladores de um processo endógeno de desenvolvimento. Este processo de desenvolvimento baseado na valorização dos recursos endógenos e na construção, participada e autónoma, de novos recursos, é um processo educativo global, de banda larga e grande riqueza e relevância.

Neste contexto, a Animação é um plano importante no modelo de Educação Comunitária, uma vez que, como refere (Ferreira, 2005);

o conceito de animação é, pois, estruturante do desenvolvimento de uma comunidade, na medida em que a educação surge associada não apenas a um objecto de intervenção (a comunidade), mas sobretudo a um sujeito, pois é a comunidade que se educa a si própria e que promove o seu desenvolvimento. (p.422).

\section{O Direito à Educação, a Animação e o Desenvolvimento na Escola Comunitária de São Miguel de Machede}

A Escola Comunitária de São Miguel de Machede assume uma matriz de intervenção social baseada na educação não formal, enquanto instrumento de construção local, participada, cooperativa, solidária e intergeracional, de acessos entre cidadãos e os respetivos deveres e direitos de cidadania (Educação, Saúde, Cultura, Proteção Social, Habitação, Trabalho, Direito, Segurança) e de laços entre todos. Este pensamento e consequente ação comunitários têm, 
como principal finalidade estratégica, desconstruir os compartimentos sociais que se sedimentaram na comunidade: jovens e seniores, mulheres e homens, escolarizados e iletrados, socialmente favorecidos e desfavorecidos, ativos e aposentados, empregados e desempregados e promover um desenvolvimento humano, social e económico sustentável, solidário e justo que garanta, a cada cidadão, as melhores oportunidades de concretizar os seus deveres e direitos de cidadania, na comunidade em que reside e desenvolve a sua atividade.

O modelo pedagógico da Escola Comunitária de São Miguel de Machede, assumindo a educação não formal, a cooperação intergeracional, a participação e a valorização dos recursos humanos locais, como elementos estruturantes, pressupõe que a construção local de repostas inovadoras, para os desafios e os problemas da comunidade, contribui para a edificação de competências territorializadas que, pela sua natureza endógena, fortalecerão as capacidades individual e coletiva e a respetiva sustentabilidade.

Em seguida, descrevem-se alguns dos projetos educacionais desenvolvidos pela Escola Comunitária de São Miguel de Machede, evidenciando-se, em cada um, alguns dos contornos do processo endógeno de Animação - frequentemente assumido e concretizado pelos membros da comunidade mais jovens e mais qualificados academicamente - e o consequente contributo no desenvolvimento humano, social e económico local.

A - Circuito da Aldeia: projeto de Educação para o Empreendedorismo - de âmbito comunitário e matriz intergeracional, na área da economia social e iniciado no ano 2009 - que disponibiliza um produto de turismo pedagógico em meio rural, destinado a jovens urbanos e oriundos de contextos escolares ou institucionais, pessoas com necessidades educativas especiais e grupos de seniores institucionalizados. Este projeto cria um roteiro de aprendizagem que contempla o contacto com as atividades e rotinas de uma pequena comunidade local, nas suas diversas circunstâncias vitais (economia, cultura, ambiente, desporto, instituições, famílias e pessoas) através de diferentes estações de aprendizagem (padaria, horta, adega, galinheiro, artesanato, jogos tradicionais, literatura tradicional, almoço familiar, percurso natural). $\mathrm{O}$ projeto proporciona o envolvimento da comunidade, combate o isolamento e promove o envelhecimento ativo, através da interação intergeracional. Através deste projeto, a comunidade conseguiu criar um produto com valor económico e, com isso, tem vindo a gerar algumas receitas próprias, promovendo um trabalho de cooperação e de intergeracionalidade entre os mais velhos (mais experientes e detentores do conhecimento experiencial) e os mais novos (menos experientes e detentores do conhecimento académico). A riqueza gerada é utilizada, preferencialmente, para suportar os encargos decorrentes das remunerações dos jovens qualificados que exercem, profissionalmente, a sua atividade na Escola Comunitária de São Miguel de Machede;
B - Gabinete da Papelada: espaço de acompanhamento dos processos administrativos e burocráticos dos utentes do Centro Comunitário local e que envolve a articulação com as entidades públicas e privadas, com as quais os cidadãos se relacionam, no quotidiano e na sequência da resolução dos problemas com que se confrontam para exercer os seus direitos e deveres de cidadania. No âmbito deste projeto, são os mais jovens e mais qualificados que realizam a mediação entre os cidadãos e as instituições. Dessa forma, estes jovens, enquanto resolvem os problemas que lhes são entregues pelos mais velhos, constroem competências que lhes vão ser essenciais na vida futura e que ficarão instaladas na comunidade. Por outro lado, a existência, no território, de uma instituição que assegura, a todos, um acesso, mais fácil e eficaz, ao exercício dos deveres e direitos de cidadania, possibilita uma perceção de apoio próximo e disponível, através do recurso a conhecimentos e competências endógenos e soluções locais, transmitindo um sentimento de maior autonomia à comunidade (Nico \& Nico, 2016).

C - Gabinete do Desenrascanço Estudantil: projeto de promoção do Sucesso Escolar e de Responsabilidade Social Individual, a partir de uma abordagem de mentorado e tutoria estudantis, baseado no modelo PADéCA (Programa de Auxílio ao Desenvolvimento da Capacidade de Aprender (Berbaum, 1992). Neste projeto, os jovens organizamse, de forma autónoma num grupo de trabalho, no âmbito do qual os mais experientes e com maior nível de escolaridade dão apoio aos mais novos, mais inexperientes e que frequentam os níveis de escolaridade mais baixos. Os jovens com formação superior assumem o papel de tutores dos restantes. O Gabinete da Papelada existe há cerca de duas décadas e já foi participado por algumas dezenas de jovens, alguns dos quais conseguiram ter longos percursos académicos que os levaram a concluir licenciaturas e mestrados. Alguns destes jovens, entretanto, iniciaram a sua atividade profissional na própria Escola Comunitária, através da realização de Estágios Profissionais;

D - Biblioteca Comunitária - projeto educacional de âmbito comunitário, concretizado desde 1998, que visa a promoção da leitura e a recolha, valorização e divulgação do património material e imaterial locais. No início, a Biblioteca Comunitária resumia-se a um projeto de distribuição de jornais, de forma domiciliar, gratuita e diária. Com o tempo, o projeto evoluiu para a instituição física de uma biblioteca, que, na atualidade, conta com cerca de 7000 títulos e que se encontra disponível para todos os membros da comunidade. Em 2008, a atividade da Biblioteca Comunitária foi reconhecida pela Fundação Calouste Gulbenkian, no âmbito do Concurso para Recuperação, Tratamento e Organização de Acervos Documentais. Através do apoio financeiro recebido, desenvolveu o projeto "Palavrão" (2008-2009), que assumiu, como finalidade, a recolha do património oral da freguesia de São Miguel de Machede, nomeadamente, os contos e histórias de base oral só conhecidas pelas pessoas mais 
velhas. Esse conteúdo foi gravado, editado, escrito, ilustrado e devolvido à comunidade, através de livros e dramatizações. Mensalmente, são desenvolvidas atividades de leitura com o Jardim de Infância de São Miguel de Machede.

E - Curso de Educação Comunitária: em 1997, foi criada a primeira experiência de alfabetização de pessoas adultas, com um grupo de dez participantes. Após alguns anos, o Curso de Educação Comunitária e de Adultos foi ganhando uma estrutura curricular mais alargada e diversificada. Este projeto conta, atualmente, com 25 adultos que participam em várias áreas de aprendizagem: Informática, Dinâmicas de Grupo; Expressão Visual, Visitas de Estudo e Expressão Físico-Motora, incluindo aulas de Hidroginástica e Ginástica. A certificação que é conferida, no final de cada atividade, é de perfil social e concretiza-se, através da divulgação pública de alguns dos produtos resultantes dessa aprendizagem. Neste processo educativo, é de relevar a importância da intergeracionalidade, evidenciando-se as vantagens de uma valorização do trabalho cooperativo entre indivíduos de diferentes gerações, com diferentes saberes e experiências vitais e com diversos percursos profissionais e culturais, numa época em que as fraturas geracionais, culturais e institucionais se sobrepõem ao espírito comunitário e do bem comum (Nico \& Nico, 2016);

F - Emprego jovem qualificado: desde a sua fundação, a Escola Comunitária de São Miguel de Machede procurou assegurar, em permanência, no mínimo, dois empregos qualificados, quase sempre preenchidos por jovens da terra. A existência, no território, de uma relação positiva entre percursos longos de qualificação e trabalho qualificado foi sempre assumida, como a principal finalidade estratégica de todo o projeto de desenvolvimento humano, social e económico associado à Escola Comunitária. Esta evidência decorre do facto de, institucionalmente, sempre se terem assegurado as condições para a concretização de longos percursos de qualificação (através do Gabinete do Desenrascanço Estudantil) e garantido, a muitos dos jovens (12 casos, em duas décadas), a oportunidade de realização de um Estágio Profissional, proporcionando trabalho compatível com as suas qualificações e, quase sempre, dando início a uma carreira profissional na sua própria terra, em atividade socialmente relevante e na qual os conhecimento e competências académicas são úteis e acrescentam valor económico e social à realidade já existente. Esta, tranquila e territorializada, transição qualificação/trabalho diminui a probabilidade de saída dos jovens da sua terra de origem, durante ou imediatamente após as suas formações, facto que é, na atualidade, o maior impulso de despovoamento, jovem e qualificado, do interior de Portugal (Nico \& Nico, 2016).

\section{Conclusão}

O projeto protagonizado pela Escola Comunitária de São Miguel de Machede evidencia a forma como, numa pequena localidade rural do interior de Portugal, se tem vindo a promover um modelo de desenvolvimento humano, social e económico, no qual a educação tem vindo a assumir um papel estruturante, na forma como as diferentes gerações se envolvem na construção das melhores soluções para os desafios e problemas com que se confrontam. Os mais jovens, normalmente mais qualificados, são convocados a liderar os processos de transformação social, utilizando e valorizando os seus conhecimentos académicos, sempre numa parceria estratégica com os saberes experienciais, normalmente associados aos mais adultos. A construção de conhecimento e competência endógenos, partindo dos recursos locais, é uma finalidade transversal a todos os projetos e atividades.

\section{Referências}

Alves, Natália; Cabrito, Belmiro; Canário, Rui \& Gomes Rui (1996). A escola e o espaço local: políticas e actores. Lisboa: Instituto de Inovação Educacional.

Araújo, Helena Costa (2010). Podemos viver juntos com cidadanias parciais?. in Margarida Felgueiras \& Carlos Vieira (Eds.).Cultura escolar, migrações e cidadania. Porto: Sociedade Portuguesa de Ciências da Educação. pp. 163-174.

Arroteia, Jorge (2008). Educação e desenvolvimento: fundamentos e conceitos. Aveiro: Universidade de Aveiro.

Berbaum, Jean (1992).Desenvolver a capacidade de aprendizagem. Lisboa: Escola Superior de Educação João de Deus.

Casimiro, António (2011). O referencial de competências-chave de nível secundário no reconhecimento de adquiridos experienciais: sentido e permanência. Lisboa: Universidade de Lisboa (Dissertação de Mestrado/Policopiada).

Ferreira, Fernando (2005). O Local em Educação: animação, gestão e parceria. Lisboa: Fundação Calouste Gulbenkian.

Gadotti, Moacir (2006). Paulo Freire e a boniteza do sonho de ensinar-aprender com sentido. in Afonso Scocuglia (Org.). Paulo Freire na História do tempo presente. Porto: Edições Afrontamento. pp. 191-217.

Libâneo, José Carlos (1998). Pedagogia e pedagogos, para quê?. São Paulo: Cortez Editora.

Lopes, Marcelino Sousa (2006). Animação Sociocultural em Portugal. Amarante: IntervençãoAssociação para a Promoção e Divulgação Cultural.

Loureiro, Isabel; Marques, Abílio \& Vallgarda, Harald (1983). Círculo de Estudos: um método de trabalho em educação de adultos. Braga: Unidade de Educação de Adultos da Universidade do Minho.

Nico, Bravo \& Nico, Lurdes (2016). Educação não formal e desenvolvimento local: o caso da Escola Comunitária de São Miguel de Machede. in Atas do XI Colóquio Ibérico de Estudos Rurais. Vila Real. UTAD / (BN.C.61) / (no prelo) / http://dx.doi.org/10.5935/ref.20160134 / http://hdl.handle.net/10174/19313 
Patrício, Manuel (1982). A Educação de Adultos em Portugal - os últimos dois séculos. Proposta de conceitos fundamentais. in Manuel Patrício (Coord.). Educação de Adultos no Alentejo: contributo para a formação dos agentes educativos. Évora: Universidade de Évora. pp. 33-78.

Quintas, Helena (2008). Educação de Adultos: vida no currículo e currículo na vida. Lisboa: Agência Nacional para a Qualificação, I.P.

Rothes, Luís (1993). A centralidade da educação de adultos em Portugal e a expansão dos espaços de intervenção dos animadores. In AA.VV. Animação Comunitária. Porto: Edições ASA. pp. 16-25.

Sarramona, Jaume (1998). La animación sociocultural. in Jaume Sarramona, Gonzalo Vázquez \& Antoni Colom \& (Org.). Educación no formal.Barcelona:Ariel Educación.

Silva, Augusto Santos (1990). Educação de Adultos: educação para o desenvolvimento. Porto: Edições ASA.

Silvestre, Carlos (2003). Educação/Formação de Adultos como dimensão dinamizadora do sistema educativo/formativo. Lisboa: Instituto Piaget.

Trigo, Márcia (2001b). O presente e o futuro da educação de adultos em Portugal. Revista Portuguesa de Pedagogia, Ano 35 (1), 101-114.

Trilla, Jaume (2004). Conceito, Exame e universo da animação sociocultural in Jaume Trilla (Coord.). Animação Sociocultural - Teorias, Programas e Âmbitos. Lisboa: Instituto Piaget. 